\title{
Research Paper: Investigating the Characteristics of Tramadol-induced Seizures: A Cross-sectional Study
}

\author{
Davood Soroosh' $^{1}$, Mahdi Foroughian ${ }^{2}$, Bahram Zarmehri ${ }^{*}$
}

1. Department of Internal Medicine, School of Medicine, Sabzevar University of Medical Sciences, Sabzevar, Iran.

2. Department of Emergency Medicine, Faculty of Medicines, Mashhad University of Medical Science, Mashhad, Iran.

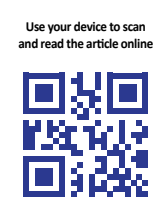

Cftation: Soroosh D, Foroughian M, Zarmehri B. Investigating the Characteristics of Tramadol-induced Seizures: A Cross-sectional Study. International Journal of Medical Toxicology and Forensic Medicine. 2020; 10(2):27869. https://doi. org/10.32598/ijmtfm.v10i2.27869

https://doi.org/10.32598/ijmtfm.v10i2.27869

(C) $0(3)$

Article info:

Received: 23 Nov 2019

First Revision: 28 Nov 2019

Accepted: 26 Dec 2019

Published: 20 Jun 2020

\section{Keywords:}

Tramadol, Seizure, Emergency, Hospital

\section{A B S TRACT}

Background: According to statistics, tramadol intoxication is one of the most common drug poisoning cases in Iran. Because seizure is one of the severe and dangerous side effects of tramadol, the present study aimed to investigate the characteristics of tramadol-induced seizures.

Methods: In this cross-sectional descriptive study, all patients who referred to the emergency departments due to the tramadol-induced seizures were examined by the census method. The patients' data were collected with a checklist. Then, the data were analyzed with descriptive and inferential statistical tests in SPSS v. 23 and at a significant level of $\mathrm{P}<0.05$.

Results: In this study, 350 patients (52.9\% male, and $47.1 \%$ female) were examined. The Mean \pm SD dose consumed was $1171.4 \pm 802.77 \mathrm{mg}$. The minimum dose that caused the seizure was $200 \mathrm{mg}$, and the average dose consumed of tramadol was different in patients who had one, two, or three seizures outside the hospital $(\mathrm{P}=0.002)$. The consumed average dose of tramadol was $1144.5 \mathrm{mg}, 2017.7 \mathrm{mg}$, and $511.1 \mathrm{mg}$ for patients who had one, two, or three seizure(s), respectively. There was a significant relationship between dose consumed and the number of seizures $(\mathrm{P}=0.001)$. The study showed that patients who had a one-time seizure, have experienced this condition outside the hospital. There was a significant relationship between the number of seizures and the location of the seizure (outside or inside the hospital) $(\mathrm{P}=0.001)$.

Conclusion: The results showed no significant relationship between consumed dose and location of the seizure. The number of seizures is not dependent on the consumed dose. It means that increasing the consumed dose, the number of seizures does not increase, and there is no significant relationship between the amount of dose consumed and the number of seizures. 


\section{Introduction}

ramadol is a synthetic and codeine-derived drug (4-phenylpiperidine codeine $\mathbf{T}$ analog) that has an analgesic application with two different mechanisms [1, 2]. Tramadol has been widely accepted as a drug with a weak $\mu$-receptor agonist activity that blocks the pain pathways and inhibits the reabsorption of biogenic amines, especially serotonin and norepinephrine in the central nervous system. It also increases the pain threshold [3]. Although it appears to be a safe and effective analgesic, the side effects related to its abuse and poisoning have been reported [4]. Statistics indicate that the abuse of tramadol is increasing in Iran [5] so that the use of tramadol has been reported as one of the most common causes of drug poisoning in recent years [6].

In most cases, tramadol overdose is not a threat to life; however, if accompanied by a seizure, the increased mortality has rarely been reported [7]. The recommended maximum dose of tramadol is $400 \mathrm{mg}$, and its overdose in the acute phase can lead to myositis, respiratory depression, seizure, hypotonicity, and acidosis. Side effects can be fatigue, vertigo, headache, visual impairments, nausea, vomiting, sweating, xerostomia (dry mouth), constipation, heart failure, and hallucination [8]. The seizure is a significant side effect of tramadol consumption and can occur following the therapeutic or toxic doses of the drug [7, 9].

One of the most dangerous side effects in patients with tramadol poisoning is the seizures. Because most physicians hospitalize these patients for fear of the second seizure, a substantial financial cost is forced on the health system. Regarding the increasing consumption of tramadol in the Iranian community and many reports of tramadol poisonings along with seizures and respiratory problems, this study aimed to investigate the characteristics of tramadol-induced seizures in the referred patients to Imam Reza and Ghaem hospitals in Mashhad.

\section{Materials and Methods}

In this cross-sectional descriptive study, the sampling of patients was initiated after approval by the Ethics Committee of Mashhad University of Medical Sciences. So that, all patients who were hospitalized with tramadol poisoning from May to September 2017 in the Emergency Departments of Ghaem and Imam Reza hospitals, were evaluated if they have presented the inclusion criteria of age between 18 to 50, hospitalization for more than 12 hours, visiting an emergency medicine specialist, and performing routine emergency care. Patients with a recent history of epilepsy and head trauma were excluded from the study.

After recording the patients' profile, inpatient followup, clinical status and related parameters, including side effects induced by poisoning, clinical status, seizure frequency, location of seizure incident, consumed dosage of tramadol, age of patients, the examination of urine toxins test, tramadol consumption history, seizure history following tramadol consumption, etc. were collected based on patients' records and documents of observations of physicians and nurses. All patients were treated according to a single guideline. Patients were monitored for up to 12 hours for the frequency of repeated seizures. Data analysis was performed using SPSS version 23 and descriptive statistical (mean, percentage, standard deviation, and frequency) and inferential statistical tests (Kruskal-Wallis, Mann-Whitney, and Chi-square) were conducted at the significant level $(\mathrm{P}<0.05)$.

\section{Results}

A total of 350 patients referred to the hospitals, of which 185 patients (52.9\%) were male, and 165 patients (47.1\%) were female. The average age of the patients was 23.4 years. The youngest was 18 , and the oldest was 47 years old. A total of 337 patients $(96.3 \%)$ have had seizures outside the hospital, and 13 patients (3.7\%) inside the hospital. The average number of seizures was 1.22 , with a minimum of one and a maximum of three. Also, 281 patients $(80.3 \%)$ had only one seizure, 60 (17.1\%) experienced two seizures, and $9(2.6 \%)$ experienced three seizures. Among the patients, 22 (6.3\%) patients had apnea following tramadol use, and $7(2 \%)$ lost their consciousness (Table 1).

The average dose consumed was $1171.4 \pm 802.77 \mathrm{mg}$, the minimum dose consumed, which had caused the seizure was $200 \mathrm{mg}$, and the maximum dose was $4000 \mathrm{mg}$.

According to the examination of urine toxins test, 269 patients $(76.9 \%)$ had only used tramadol, but 50 patients (14.3\%) opium, 17 (4.9\%) benzodiazepine, and 14 (4\%) patients amphetamine along with tramadol.

Among the patients, 157 (44.9\%) have reported the history of using tramadol, and 17 patients $(4.9 \%)$ had seizure history after consuming tramadol (Table 2).

The average dose of tramadol consumed was significantly different in patients who have had one or two or three times seizure(s) outside the hospital ( $\mathrm{P}=0.002)$. There was also a 
Table 1. Demographic characteristics of the patients

\begin{tabular}{|c|c|}
\hline Variables & No. (\%) \\
\hline Male & 185 (52.9) \\
\hline Female & $165(47.1)$ \\
\hline Seizure outside the hospital & $337(96.3)$ \\
\hline Seizure inside the hospital & $13(3.7)$ \\
\hline One seizure & $281(80.3)$ \\
\hline Two seizures & $60(17.1)$ \\
\hline Three seizures & $9(2.6)$ \\
\hline The occurrence of apnea & $22(6.3)$ \\
\hline Loss of consciousness & $7(2)$ \\
\hline
\end{tabular}

Table 2. Frequency of drug use and seizure records following drug consumption

\begin{tabular}{llc}
\hline \multicolumn{1}{c}{ Variables } & & No. (\%) \\
\hline Tramadol use history & Yes & $157(44.9)$ \\
& No & $193(55.1)$ \\
\hline Case history of seizure incident following the tramadol use & Yes & $17(4.9)$ \\
\hline & No & 333 (95.1) \\
\hline
\end{tabular}

significant difference between the average consumed doses in patients who have experienced two or three seizures inside the hospital $(\mathrm{P}=0.002)$ (Table 3 ).

Tramadol consumed average doses were $1144.5 \mathrm{mg}$, $2017.7 \mathrm{mg}$, and $511.1 \mathrm{mg}$ in patients who had one, two, and three seizure(s), respectively. According to the Kruskal-Wallis statistical test, there is a significant relationship between the dose consumed and the number of seizures $(\mathrm{P}=0.001)$ (Table 4).

Table 3. Comparison of tramadol consumed dose in three groups of patients divided by the number of seizures outside and inside the hospital

\begin{tabular}{lcccc}
\hline Variables & $\begin{array}{c}\text { Number of } \\
\text { Seizures }\end{array}$ & $\begin{array}{c}\text { Number of } \\
\text { Patients }\end{array}$ & Mean \pm SD & Result of the Kruskal-Wallis Test \\
\hline $\begin{array}{c}\text { Outside the } \\
\text { hospital }\end{array}$ & 1 & 281 & $1144.841 \pm 5.2$ & $1317.552 \pm 0.5$ \\
& 2 & 53 & $533.230 \pm 3.9$ & $\begin{array}{c}\chi^{2}=12.60 \\
P=0.002\end{array}$ \\
& 1 & 3 & - & $\chi^{2}=9.57$ \\
Inside the hospital & 2 & 0 & $2000.230 \pm 0.9$ & \\
& 3 & 7 & $500.275 \pm 0.7$ & \\
\hline
\end{tabular}


Table 4. Comparison of tramadol consumed dose in three groups of patients based on the number of seizures

\begin{tabular}{ccc}
\hline Variables & Mean \pm SD & Result of the Kruskal-Wallis Test \\
\hline One seizure & $1144.5 \pm 841.2$ & \\
Two seizures & $2017.7 \pm 568.6$ & $\chi^{2}=23.557$ \\
$\mathrm{P}=0.001$ \\
Three seizures & $511.1 \pm 247.2$ & \\
\hline
\end{tabular}

The patients with one seizure have experienced it outside the hospital. In the case of patients with two seizures, $53(88.3 \%)$ have had both seizures outside the hospital, and 7 (11.7\%) have experienced the second seizure inside the hospital. In the case of patients with three seizures, 3 patients $(33.3 \%)$ have had all three seizures outside the hospital, and $6(66.7 \%)$ have experienced the second and third seizures inside the hospital. According to the Chi-square test, there is a significant relationship between the number of seizures and the location of the seizure incident $(\mathrm{P}=0.001)$.

\section{Discussion}

Currently, patients who refer to the hospital complaining of taking tramadol, are being monitored in the emergency room for several hours, depending on the clinical status and concomitant use of other drugs. Then if their seizure and clinical condition are being controlled and stable, they get discharge [10]. This study aimed to investigate the characteristics of tramadol-induced seizures.

In the present study, the average age of patients was 23.4 years. The average age of patients in the studies of Delirrad et al., Jovanović, and Abbasi et al. were respectively $23.29,22.2$, and 23.23 years, which are close to the present study and may indicate the prevalence of this phenomenon among the young people $[10,11,12]$. The youth are also more likely to abuse drugs such as tramadol since they are more involved in risky behaviors. The availability of the drug, not knowing the side effects of tramadol, and the recommendation of peer groups and friends to take tramadol as a common painkiller have increased the use of this drug in Iran. This situation mostly underscores the importance of education about the dangers and side effects of random use of addictive drugs at the community level, especially young people $[7,13]$.

In the present study, tramadol consumption was higher in men. In Bushehri et al. study, tramadol consumption was also higher in men [14]. Also, the results of Mood et al., Farzaneh et al., Okazi et al., Shokrzadeh et al., Delirrad et al., Talaei et al. support the results of the present study [5, 6, 11, 16-18]. But the results of by Spiller et al. study and Marquardt et al. in the USA were different, in which women had been poisoned more than men due to the cultural differences between Iran and USA regarding the tendency of women to use drugs $[19,20]$. Tramadol is also more commonly prescribed in other countries as a painkiller and can lead to unwanted poisoning, but in our country, tramadol is abused, and adult patients (especially women) use it like other drugs with the aim of suicide. In the present study, the Mean \pm SD consumed dose of tramadol was $1171.4 \pm 802.77 \mathrm{mg}$.

In the studies of Mood et al., Taghaddosi Nejad et al., and Delirrad et al., the Mean \pm SD consumed dose of tramadol were $2006 \pm 7466,1151 \pm 1353$, and $2347.36 \pm 1837.35$ mg, respectively $[6,11,21]$. In this study, the minimum dose consumed of tramadol that caused seizure was 200 $\mathrm{mg}$ and the maximum dose of $4000 \mathrm{mg}$ among the patients. In a retrospective study done by Klarout et al. in the USA, the minimum consumed dose of tramadol that resulted in seizure was $500 \mathrm{mg}$, and the minimum dose that caused coma and respiratory depression was $800 \mathrm{mg}$ [22]. In the study of Mood et al., the minimum consumed dose and the maximum dose consumed were reported to be 100 and $10000 \mathrm{mg}$, respectively [6].

In Jovanović et al. study, the lowest and highest doses associated with seizures were respectively 250 and $2500 \mathrm{mg}$ [12]. Farzaneh et al. reported the minimum dose of $100 \mathrm{mg}$ related to seizure [15], and in Mehrpour et al. study, two cases of seizures with the doses of $100 \mathrm{mg}$ were reported [23]. Also, in the investigations conducted by Spiller et al. and Marquardt et al., the minimum doses related to seizure were reported to be $500 \mathrm{mg}$ and $800 \mathrm{mg}$, respectively [19, 20]. Besides, in Delirrad et al. research, the tramadol consumption was $100 \mathrm{mg}$, and the maximum consumed dose was $8000 \mathrm{mg}$ [11]. These differences can be attributed to the independence of seizure incident from the consumed dose in patients with tramadol poisoning.

In the present study, $44.9 \%$ of patients had a history of tramadol use. The percentages of patients who reported the history of tramadol use were $78.5 \%, 34 \%, 66.4 \%$, 
and $58.7 \%$ in the study of Bushehri et al., Mood et al., Farzaneh et al., and Abbasi et al., respectively [6, 10, 14, 15]. The frequent consumption of tramadol may be due to excessive dependence on the drug. It appears that these results indicate the drug abuse by young people. Also, the ease of access and preparation of suicide is one of the essential aspects in this area and should be considered.

Respiratory apnea (6.2\%) was the most common cause of patients' referral to hospitals. In a study conducted on 190 poisoning cases with tramadol in the USA, the most commonly reported clinical symptom was respiratory distress that occurred in $27.4 \%$ of poisoned patients [24]. In the studies of Mood et al. [6], Bushehri et al. [14], Shokrzadeh et al. [17], Delirrad et al. [11], Mood et al. [6], Farzaneh [15], and Marquardt [20], the most common causes of patients' referral was the loss of consciousness. Regarding these reports, it appears that the symptoms of poisoning with tramadol are due to the inhibitory effects of tramadol on catecholamines and serotonin reabsorption rather than to the opioid effects of the drug. Dysphonia, tachycardia, vertigo, and hypertension all can indicate mild serotonin syndrome. Also, consuming high doses of tramadol causes severe involvement of the nervous system, but not the cardiovascular system [24].

In the present study, the examination of urine toxins test indicated that $76.9 \%$ of patients had only used tramadol, and respectively 50,17, and 14 patients had consumed opium, benzodiazepine, and amphetamine along with tramadol. In the study of Bushehri et al. [14], 41 patients (17.6\%) did not take a concomitant drug with tramadol, 185 patients (79.4\%) had concomitant drug use along with tramadol, and 7 (3\%) had uncertain status. In Mood et al. study [6], 100 patients $(54.3 \%)$ had only used tramadol, and the rest had taken other medications in addition to tramadol; the most common drugs were clonazepam and acetaminophen. In Delirrad et al. study [11], 38 patients $(15 \%)$ reported concomitant use of other drugs, and 213 patients $(83.9 \%)$ had used only tramadol. The reason for taking tramadol with other drugs or medications may be the fact that the aim of the majority of patients was committing suicide; hence, they had accidentally used other medicines in addition to tramadol [15].

In the present study, the rate of seizure following tramadol use was $4.9(n=17)$ (Table 2), which was the most important seizure factor in drug poisonings in Isfahan (25\%), Ardabil (28.3\%), Urmia (41.3\%), Tehran (46.2\%). Gorgan (35.1\%) and France $(27.4 \%)$ [6, 11, 15, 17, 18, 20].

In this study, there was a significant relationship between the consumed dose of tramadol and seizure outside and inside the hospital (Table 3). The results of the present study are consistent with the studies of Mood et al. [6], Marquardt et al. [20], and Abbasi et al. [10]. In the investigations of Farzaneh et al. [15], Tashakkori et al. [25], Delirrad et al. [11], the amount of consumed dose of tramadol was not significantly correlated with the seizure, which does not support the results of the present study.

In the present study, there was no significant relationship between the previous history of addiction to tramadol and the seizure incidence. The results of the present study are consistent with the studies of Farzaneh et al. [15] and Taghaddosi Nejad et al. [21]. Studies by Jovanovic-Cupic et al. [12] and Marquardt et al. [20] indicate a relationship between tramadol addiction and the seizure incidence, which does not support the results of the present study.

In the present study, $80.3 \%, 17.1 \%$, and $2.6 \%$ of patients had respectively one, two, and three seizures. In Jovanović-Čupić et al. study, $45 \%$ of patients who experienced seizures, had only one seizure, and $55 \%$ of them had more than one seizure [12]. In Abbasi et al. study [10], the patients were divided into two groups according to the frequency of seizures: patients with one seizure and patients with two and more seizures. In the first group, the time interval between drug use and seizure was approximately 3.5 hours. However, in patients who had two or more seizures, the occurrence time of the first seizure was less than one hour, and the occurrence time of second seizure was reported to be less than three hours. In other words, the probability of the second seizure was less, and its time interval with the first seizure was less than two hours.

The patients with one seizure experienced it outside the hospital. In the patients who had two seizures, both seizures occurred outside the hospital in $88.3 \%$ of cases, and inside the hospital in $11.7 \%$ of patients. Among the patients who had three seizures, $33.3 \%$ had all three seizures outside the hospital, and $66.7 \%$ of them had the second and third seizures inside the hospital. Abbasi et al. study indicates that the average seizure time is less than the average time of referral, indicating that at least the first seizure was before the referral, and patients had referred to the treatment center after the first seizure [10].

\section{Conclusion}

The results of the present study suggested no significant relationship between the consumed dose and location of seizure incident (outside and inside the hospital). The consumed doses of tramadol are different in the patients who have had two or three seizures, but this difference is 
not dose-dependent. In other words, by increasing dose, the number of seizures does not increase, and there is no significant relationship between the amount of consumed dose and the number of seizures.

\section{Ethical Considerations}

\section{Compliance with ethical guidelines}

All ethical principles were considered in this article.

\section{Funding}

This research did not receive any specific grant from funding agencies in the public, commercial, or not-forprofit sectors.

\section{Author's contributions}

All authors contributed in preparing this article.

\section{Conflict of interest}

The authors declared no conflict of interest.

\section{Acknowledgements}

Special thanks to the Vice Chancellor's Office for Research of Mashhad University of Medical Sciences for funding this project. The authors also appreciate all the nurses and physicians who assisted in carrying out this study. Moreover, the authors would like to thank the Clinical Research Development Unit of Peymanieh Hospital for their assistance in writing this article.

\section{References:}

[1] Odonkor CA, Chhatre A. What's tramadol got to do with it? A case report of rebound hypoglycemia, a reappraisal and review of potential mechanisms. Pain Physician. 2016; 19(8):E1215-20. https://www.ncbi.nlm.nih.gov/pubmed/27906953

[2] Barann M, Stamer UM, Lyutenska M, Stüber F, Bönisch H, Urban B. Effects of opioids on human serotonin transporters. Naunyn Schmiedebergs Arch Pharmacol. 2015; 388(1):43-9. [DOI:10.1007/s00210-014-1056-3] [PMID]

[3] Emamhadi M, Sanaei-Zadeh H, Nikniya M, Zamani N, Dart RC. Electrocardiographic manifestations of tramadol toxicity with special reference to their ability for prediction of seizures. Am J Emerg Med. 2012; 30(8):1481-5. [DOI:10.1016/j. ajem.2011.12.009] [PMID]

[4] Hassanian Moghaddam H, Farajidana H, Sarjami S, Owliaey H. Tramadol-induced apnea. Am J Emerg Med. 2013, 31(1):26-31. [DOI:10.1016/j.ajem.2012.05.013] [PMID]
[5] Asadi P, Kasmaei VM, Ziabari SZ, Zohrevandi B, Manesh AM. Prevalence of tramadol consumption in first seizure patients; A one-year cross-sectional study. Emerg (Tehran). 2015; 3(4):159-61. https://www.ncbi.nlm.nih.gov/pubmed/26495407

[6] Mood NE, Sabzghabaee AM, Safdari A, Yaraghi A. Clinical signs, hospitalization duration and outcome of tramadol intoxication. J Isfahan Med Sch. 2011; 28(117):1187-93. https:/ www.sid.ir/en/journal/ViewPaper.aspx?id=221191

[7] Shadnia S, Brent J, Mousavi-Fatemi K, Hafezi P, Soltaninejad K. Recurrent seizures in tramadol intoxication: Implications for therapy based on 100 patients. Basic Clin Pharmacol Toxicol. 2012; 111(2):133-6. [DOI:10.1111/j.1742-7843.2012.00874.x] [PMID]

[8] Boostani R, Derakhshan S. Tramadol induced seizure: A 3-year study. Caspian J Intern Med. 2012; 3(3):484-7. https:/ / www.ncbi.nlm.nih.gov/pubmed/24009919

[9] Chen HY, Albertson TE, Olson KR. Treatment of druginduced seizures. Br J Clin Pharmacol. 2016; 81(3):412-9. [DOI:10.1111/bcp.12720] [PMID] [PMCID]

[10] Abbasi B, Hafezimoghadam P, Ansari Nejad N , Sarvari M Ramim T. [Assessment of time interval between tramadol intake and seizure and second drug-induced attack (Persian)] Tehran Univ Med J. 2015; 73(8):592-9. http:/ / tumj.tums.ac.ir/ article-1-6966-en.html

[11] Delirrad M, Ebrahimi E, Majidi M. [Evaluation of demographic characteristics and renal function indices in acute tramadol intoxicated patients in ayatollah Taleghani hospital, Urmia, Iran (Persian)]. Stud Med Sci. 2015; 25(12):1060-6. http:/ / umj.umsu.ac.ir $/$ browse.php?a_id=2677\&sid=1\&slc_lang=en

[12] Jovanović-Čupić V, Martinović Ž, Nešić N. Seizures associated with intoxication and abuse of tramadol. Clin Toxicol (Phila) 2006; 44(2):143-6. [DOI:10.1080/1556365050014418] [PMID]

[13] Goodarzi F, Mehrpour O, Eizadi-Mood N. A study to evaluate factors associated with seizure in tramadol poisoning in Iran. Indian J Forensic Med Toxicol. 2011; 5(2):66-9. https:// www.indianjournals.com/ijor.aspx?target=ijor:ijfmt\&volum $\mathrm{e}=5$ \& issue $=2$ \&article $=022$

[14] Boushehri B,Dalir Raad M, Valizad Hasanlouee MA Jaaberi M. Evaluation of clinical findings and acute compilications in patient's admitted to Urmia Taleghani Hospital with tramadol intoxication at 2012- 2013. Iran J Assoc of Anesthesiol and Crit Care. 2014; 36(85):41-9. https:/ /www.magiran. $\mathrm{com} /$ paper/1285576?lang=en

[15] Farzaneh E, Samadzadeh M, Shahbazzadegan B, Sayadrezai I, Mostafazadeh B, Sarbandi Farahani A, et al. Comparing the frequency of seizure in patients intoxicated with tramadol treated with or without naloxone. J Isfahan Med Sch. 2012; 30(197):1012-8. https://www.researchgate.net/ publication/324555811_Comparing_the_frequency_of_seizure_in_patients_intoxicated_with_tramadol_treated_with_ or_without_naloxone

[16] Okazi A, Taghaddosinejad F, Mazrouei N, Forouzeh M, Barzegar A, Fallah F. Occurrence and recurrence of seizures and related factors in patients with tramadol ingestion. Int J Med Toxicol Forensic Med. 2018; 8(3):101-8. [DOI:10.22037/ ijmtfm.v8i3(Summer).22053]

[17] Shokrzadeh M, Hajimohammadi A, Delaram A, Shayeste Y Characteristics of patients hospitalized with tramadol intoxi- 
cation in Gorgan, Iran, 2008 - 2015. J Mazandaran Univ Med Sci. 2017; 26(146):185-90. http:/ / eprints.goums.ac.ir/5084/

[18] Talaie H, Panahandeh R, Fayaznouri M, Asadi Z, Abdollahi M. Dose-independent occurrence of seizure with tramadol. J Med Toxicol. 2009; 5(2):63-7. [DOI:10.1007/BF03161089] [PMID] [PMCID]

[19] Spiller HA, Gorman SE, Villalobos D, Benson BE, Ruskosky DR, Stancavage MM, et al. Prospective Multicenter evaluation of tramadol exposure. J Toxicol Clin Toxicol. 1997; 35(4):361-4. [DOI:10.3109/15563659709043367] [PMID]

[20] Marquardt KA, Alsop JA, Albertson TE. Tramadol exposures reported to statewide poison control system. Ann Pharmacother. 2005; 39(6):1039-44. [DOI:10.1345/aph.1E577] [PMID]

[21] Taghaddosinejad F, Mehrpour O, Afshari R, Seghatoleslami A, Abdollahi M, Dart RC. Factors related to seizure in tramadol poisoning and its blood concentration. J Med Toxicol. 2011; 7(3):183-8. [DOI:10.1007/s13181-011-0168-0] [PMID] [PMCID]

[22] Clarot F, Goulle JP, Vaz E, Proust B. Fatal overdoses of tramadol: Is benzodiazepine a risk factor of lethality? Forensic Sci Int. 2003; 134(1):57-61. [DOI:10.1016/S0379-0738(03)00100-2]

[23] Mehrpoure M. Intravenous tramadol-induced seizure: Two case reports. Iran J Pharmacol Ther. 2009; 4(2):146-7. http:/ / www.bioline.org.br/pdf?pt05031

[24] Michaud K, Augsburger M, Romain N, Giroud C, Mangin P. Fatal overdose of tramadol and alprazolam. Forensic Sci Int. 1999; 105(3):185-9. [DOI:10.1016/S0379-0738(99)00118-8]

[25] Tashakori A, Afshari R. Tramadol overdose as a cause of serotonin syndrome: A case series. Clin Toxicol (Phila). 2010; 48(4):337-41. [DOI:10.3109/15563651003709427] [PMID] 
This Page Intentionally Left Blank 